ISSN electrónico: 2445-1355

DOI: http://dx.doi.org/10.14201/fj2020512736

\title{
NANOPARTÍCULAS DE PLATA COMO AGENTE ANTIBACTERIANO EN INFECCIONES ÓSEAS
}

\section{Silver nanoparticles as antibacterial agents in bone tissue infections}

\section{Adela GONZÁLEZ-JIMÉNEZ; Ana GARCÍA}

Departamento de Química Inorgánica y Bioinorgánica, Facultad de Farmacia, Universidad Complutense de Madrid, Plaza Ramón y Cajal, s/n, 28040 Madrid Correo-e: adelag01@ucm.es, anagfontecha@ucm.es

RESUMEN: El envejecimiento progresivo de la población y el aumento de las afecciones articulares degenerativas generan un incremento en las patologías óseas, comprometiendo al aparato locomotor. Esto da lugar a un aumento de fracturas y defectos óseos, difíciles de tratar en algunos casos.

Los avances en la ciencia de materiales y la biomedicina son determinantes en este ámbito, ya que buscan diseñar nuevos biomateriales para posteriormente implantarlos con el fin de reemplazar, reparar y regenerar el tejido óseo dañado. Sin embargo, en algunas ocasiones, su aplicación clínica puede presentar varios problemas. Uno de estos problemas es la posible infección bacteriana tras la intervención quirúrgica, que generaría la formación de un biofilm. Esto puede inhibir el efecto de antibióticos en esa zona, requiriendo una segunda intervención quirúrgica. La plata es un agente citotóxico que podría utilizarse como medida preventiva para evitar la formación de un biofilm bacteriano en implantes, mediante su incorporación al propio biomaterial.

El propósito de este trabajo es documentar el uso de las nanopartículas de plata metálica como agente antibacteriano. Se indicará su mecanismo de acción frente a las bacterias y su posible toxicidad en el organismo humano.

Palabras clave: Biomateriales; regeneración de hueso; biofilm; nanopartículas de plata; propiedades antibacterianas. 
ABSTRACT: Bone tissue engineering is an area of increasing interest because its main applications are directly related to the rising life expectancy of the population, so innovative strategies are needed for bone tissue regeneration therapies. Advances in biomedicine and materials science are determining factors in this field, since they pursue to design new biomaterials to subsequently implant them in order to replace, repair and regenerate damaged bone tissue.

Post-operative implant infections are one of the most serious complications associated with surgical treatments of bone diseases. Bacteria typically secrete polymeric materials after their association to form protective coatings known as biofilms. Biofilm further impedes the activity of the host defenses and/or antibiotic therapy, requiring surgical intervention to remove the implant as the only effective option. Silver is an antibacterial agent that could be used as a preventive measure to avoid the formation of a bacterial biofilm in implants by incorporation of metallic silver nanoparticles.

The present work is focused in finding a preventive treatment of bone infection with metallic silver nanoparticles embedded. It describes their behavior as antibacterial agents and possible toxicity.

Keywords: Biomaterials; bone regeneration; biofilm; mesoporous bioactive glasses; silver nanoparticles; antibacterial properties.

\section{INTRODUCCIÓN}

El aparato locomotor está formado por el sistema óseo y el sistema muscular. Permite realizar funciones vitales a la vez que sirve de sostén y protección de los órganos del cuerpo.

El envejecimiento progresivo y el aumento de las afecciones articulares degenerativas producen un incremento en las patologías óseas, comprometiendo al aparato locomotor. Esto da lugar a un aumento de fracturas y defectos óseos, difíciles de tratar en algunos casos. Los avances en la ciencia de materiales y biomedicina son determinantes en este ámbito, ya que buscan crear materiales con el fin de reemplazar, reparar y regenerar el tejido óseo dañado.

Los biomateriales se clasifican en 3 familias: metales, polímeros y cerámicas. Estas últimas se subdividen en 3 generaciones (Salinas, Vallet-Regí, 2007). La tercera generación sustituye y regenera tejido óseo dañado debido a su alta bioactividad. Gracias a su gran superficie específica sirven como soportes para células y sustancias biológicamente activas (factores de crecimiento, proteínas...)

Ediciones Universidad de Salamanca / Ф@ఠ $\quad$ FarmaJournal, vol. 5, núm. 1 (2020), pp. 27-36 
que se liberan de forma sostenida y favorecen estimulación celular necesaria para la regeneración ósea.

Hoy en día, las técnicas quirúrgicas y el uso de biomateriales es una solución a las patologías óseas. Uno de sus principales problemas radica en la infección bacteriana del implante, pudiéndose formar un revestimiento de bacterias sobre el implante, es decir, se forma un biofilm que puede inhibir el efecto de antibióticos en esa zona, requiriendo una segunda intervención quirúrgica que aumenta el riesgo y el coste del tratamiento y el sufrimiento del paciente.

La formación del biofilm ocurre en diferentes etapas (Gupta et al., 2016): (1) Invasión: unión reversible de las bacterias planctónicas sobre la superficie; (2) Colonización: las bacterias se unen de forma irrreversible a la superficie por ligandos específicos formando microcolonias; (3) Maduración del biofilm: mientras las bacterias se dividen activamente, liberan EPS (sustancias poliméricas extracelulares) que forman el soporte para el biofilm, y (4) Desprendimiento activo: las capas más externas presentan bacterias planctónicas que se desplazan para colonizar nuevas superficies.

La plata (Ag) es un metal de transición con número atómico 47 que se encuentra en el grupo 11 de la tabla periódica. En el campo de la ciencia de materiales y ciencias de la salud, presenta una actividad antimicrobiana que le ha permitido incorporarse a los productos sanitarios (Figura 1) en vendajes, catéteres, pastas, cementos e implantes dentales.

Figura 1: Aplicaciones actuales de los diferentes compuestos de plata en el cuerpo humano. Imagen adaptada de referencia (Chaloupka et al., 2010)

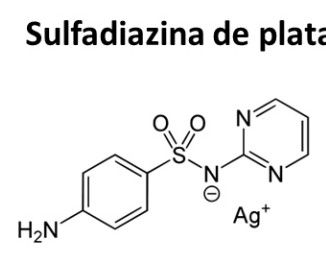

Nitrato de plata<smiles>[13CH3][N+]([O-])([O-])[O-]</smiles>

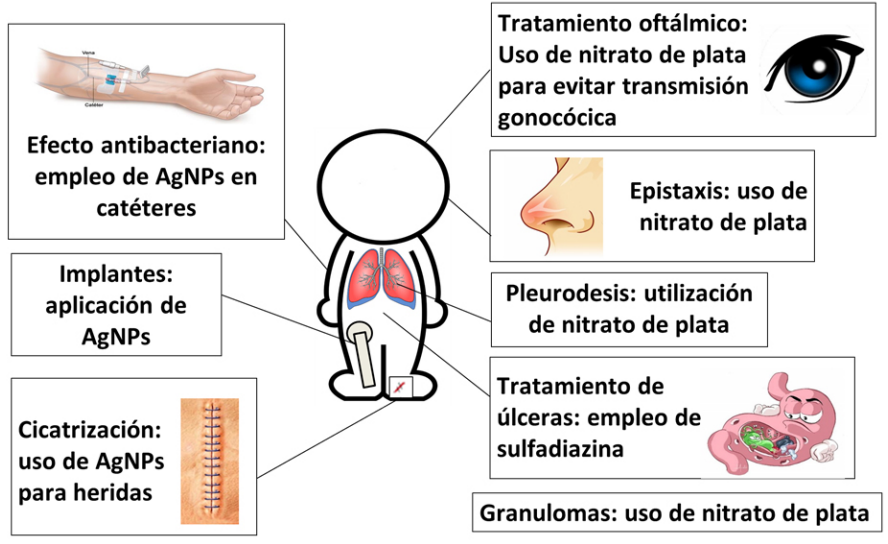


Su efecto antibacteriano se conoce desde la antigüedad. Los romanos ya utilizaban vasos de plata para mantener el agua libre de microorganismos, Hipócrates (siglos V-IV a. C.) la utilizaba en bebidas para tratar úlceras y Avicena (siglos $\mathrm{X}-\mathrm{XI}$ ) para purificar la sangre (Alexander, 2009).

Actualmente, su forma de uso más común es la sal nitrato de plata $\left(\mathrm{AgNO}_{3}\right)$ y se utiliza impregnándose en numerosos vendajes como antiséptico en heridas (Ducheyne, 2017). Otro derivado de plata muy utilizado desde 1960 es la sulfadiazina argéntica, que sirve para el tratamiento de quemaduras (Alexander, 2009).

Los avances científicos han permitido desarrollar nuevos campos en el ámbito de la medicina, como es el caso de la nanomedicina. Esto ha permitido un progreso en el uso de la plata en la medicina, ya que se está comenzando a emplear en forma de nanopartículas embebidas en biomateriales y formar así nanomateriales.

Anteriormente en este trabajo se hablaba del problema que supone la infección de un implante óseo. Una posible solución es el empleo de nanomateriales, especialmente los que incluyen AgNPs. Recientes estudios (Qing et al., 2018) relacionan el uso de AgNPs con un aumento de la fosfatasa alcalina (enzima hidrolítica cuyo déficit se da como respuesta a un deterioro óseo) y del gen Bmp6 (iniciador de la diferenciación de osteoblastos).

En el caso de las nanopartículas de plata (AgNPs) se presentan en forma de clústeres de átomos de plata con un diámetro de 1 a $100 \mathrm{~nm}^{3}$. El uso de AgNPs presenta la ventaja de que su tamaño le permite entrar en el interior de las bacterias. Sin embargo, también puede penetrar en el interior de células, por lo que hay que tener en cuenta su toxicidad, que se comentará posteriormente.

\section{2. Овjetivos}

Debido a la evolución de la nanomedicina en el campo de los implantes óseos y el aumento de resistencias a antibióticos, este trabajo tiene los siguientes objetivos:

- Describir los diferentes métodos de obtención de nanopartículas de plata (AgNPs).

- Describir el mecanismo de acción de las AgNPs como agentes antibacterianos.

- Valorar la aplicación de las AgNPs en implantes óseos para la prevención de infecciones.

- Analizar la posible toxicidad de las AgNPs en el ser humano. 


\section{Metodología}

Este trabajo se ha realizado mediante una revisión bibliográfica de libros y artículos científicos recogidos en bases de datos como PubMed, Google Scholar, Scopus y Web Of Science.

Se busca mostrar una recopilación del uso actual de nanopartículas de plata en biomateriales para su posible aplicación como agente antibacteriano.

\section{Resultados y discusión}

\subsection{Sintesis de nanopartículas de plata metálica (AgNPs)}

Existen númerosos metodos de síntesis de AgNPs, todos ellos basados en la reducción de $\operatorname{Ag}(\mathrm{I})$ a $\operatorname{Ag}(0)$. Se puede controlar el tamaño y forma de las nanopartículas a través de la modificación de la velocidad de reacción. Para la síntesis de las AgNPs se requiere la presencia de 3 componentes (Monge, 2009):

- Precursor metálico que contenga Ag (por ejemplo, AgNO3).

- Agente reductor que genere la reducción de la plata de $\mathrm{Ag}^{+}$a $\mathrm{Ag}^{0}$.

- Agente estabilizante que favorezca o facilite la reacción. Por ejemplo, el ácido cítrico, aunque en los últimos años algunos estudios (Monge, 2009) han demostrado que no es imprescindible, puesto que el alto potencial de reducción de la Ag hace que la oxidación de las AgNPs no sea favorable termodinámicamente.

Figura 2: Síntesis de AgNPs, Imagen adaptada de referencia

(Chaloupka et al., 2010)



Ediciones Universidad de Salamanca / @@ఠ $\quad$ FarmaJournal, vol. 5, núm. 1 (2020), pp. 27-36 
El proceso de síntesis tiene lugar en dos fases (Figura 2): la primera consiste en la nucleación de los átomos de plata libres y requiere una alta energía de activación; la segunda se basa en el crecimiento de los núcleos formados en la etapa anterior, por lo que la energía de activación necesaria es baja.

\subsection{Propiedades antibacterianas de la plata}

El mecanismo de acción de la plata como agente antibacteriano no está totalmente elucidado, aunque diversas fuentes biobliográficas apuntan a que la plata tiene 3 puntos de acción fundamentales (Chaloupka et al., 2010; Ducheyne, 2017) (Figura 3):

- Por un lado, es capaz de producir la desnaturalización de las proteínas de la membrana plasmática, permitiendo la entrada de plata. También se cree que puede producir la desnaturalización de los ribosomas una vez se encuentra en el citoplasma.

- Su afinidad por nitrógeno y fósforo le permite unirse al ADN citoplasmático bacteriano, produciendo daños a este nivel.

- Presenta afinidad por grupos tioles (-SH) de los aminoácidos que forman las enzimas implicadas en la cadena de trasporte electrónico de la respiración, aumentando el estrés oxidativo y produciendo especies reactivas de oxígeno (ROS).

Se postula que la actividad antibacteriana está directamente relacionada con la liberación de iones $\mathrm{Ag}^{+}$. La reacción que tiene lugar es la oxidación en disolución acuosa cuando se libera la plata en condiciones ácidas (Zong-min et al., 2012):

$$
\begin{gathered}
4 \mathrm{Ag}+\mathrm{O} 2 \rightarrow 2 \mathrm{Ag} 2 \mathrm{O} \\
2 \mathrm{Ag} 2 \mathrm{O}+4 \mathrm{H}^{+} \rightarrow 4 \mathrm{Ag}^{+}+2 \mathrm{H} 2 \mathrm{O}
\end{gathered}
$$

Si nos ceñimos al campo de las infecciones óseas, si se lograra modular esta liberación de cationes $\mathrm{Ag}^{+}$del soporte implantado que contiene $\mathrm{Ag}$ en el defecto óseo se podría a su vez regular la actividad antibacteriana tras la cirugía evitando la infección en la zona y la retirada del implante (Hidron et al., 2008). La liberación se produce siguiendo una cinética exponencial (Figura 4), siendo muy rápida al principio y disminuyendo la velocidad con el paso del tiempo (Loza et al., 2014).

La presencia de oxígeno es un factor necesario para que la plata se libere y ejerza efecto antibacteriano. Existen estudios en los que se ha investigado la inhibición del crecimiento bacteriano de Staphylococcus aureus (Figura 5), en condiciones de aerobiosis y anaerobiosis, siendo sólo efectiva en las primeras (Loza et al., 2014). 
Figura 3: Mecanismo de acción de los iones $\mathrm{Ag}^{+}$. Imagen adaptada de referencia (Chaloupka et al., 2010)

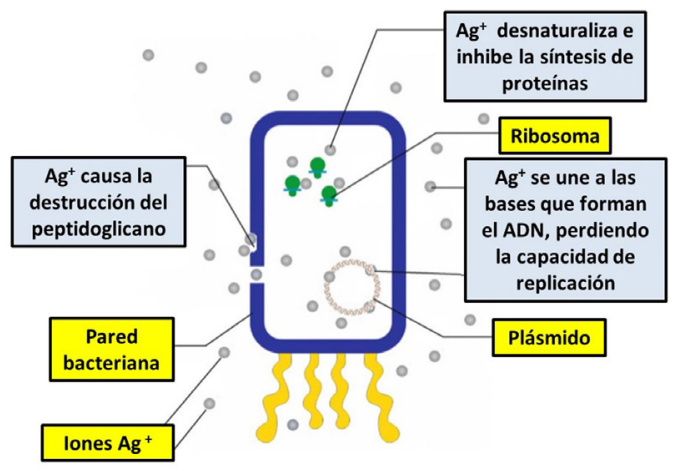

Figura 4: Liberación de iones $\mathrm{Ag}^{+}$en agua destilada y disolución salinas $(\mathrm{NaCl}$ 0,9\% y PBS). Imagen adaptada de referencia (Loza et al., 2014)
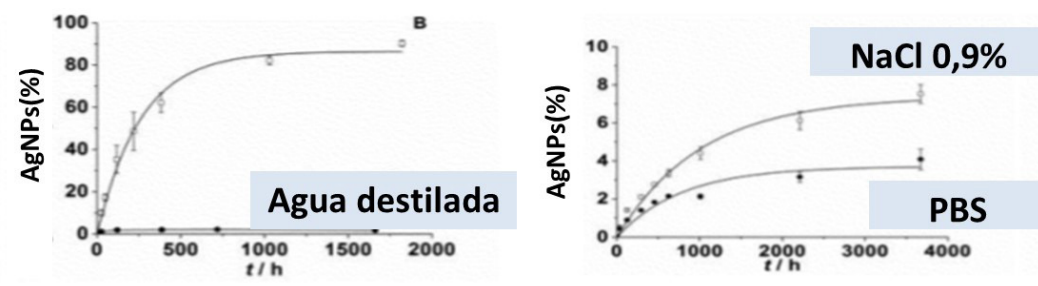

FIgura 5: Efecto antibacteriano de AgNPs para S. aureus en condiciones de anaerobiosis (izquierda) y aerobiosis (derecha). Imagen adaptada de referencia (Loza et al., 2014)



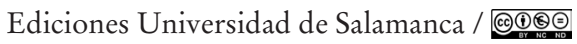
FarmaJournal, vol. 5, núm. 1 (2020), pp. 27-36 


\subsection{Toxicidad de las AgNPs en el organismo bumano}

Fuentes bibliograficas citan que la concentración toxica de la plata metálica es de $1-10 \mathrm{mg} / \mathrm{L}$ (Chernousova y Epple, 2013; Lansdown, 2006). Sin embargo, también indican que si se administra en forma de nanopartículas puede alcanzar concentraciones de entre 10 y $100 \mathrm{mg} / \mathrm{L}$ sin presentar toxicidad.

Algunos estudios han demostrado que la cantidad tóxica de plata administrada en una toma, y en concreto para humanos, es de $500 \mathrm{mg} / \mathrm{kg}$ de peso (Chatterjee, 2015), aunque en otros estudios (Chernousova y Epple, 2013; Lansdown, 2006) se ha demostrado que a partir de $10 \mathrm{mg} / \mathrm{L}$ presenta efectos nocivos en el desarrollo embrionario y que formas de adminitración oral de plata pueden disminuir la flora intestinal comensal.

La ventaja del uso de AgNPs frente a plata es que no solo se pueden alcanzar concentraciones mayores por dosis, sino que la toxicidad intrínseca de las nanopartículas va a depender de su tamaño, forma, solubilidad, superficie específica, carga superficial y aglomeración que presente (Lansdown, 2006). Serán menos tóxicas las partículas de mayor tamaño (penetran menos en el organismo), que estén más compactas (disminuye el área superficial para interaccionar), tengan forma esférica (ya que al tener menos caras que las poliédricas son menos reactivas) e insolubles (interaccionan menos).

Si hay una sobreexposición de plata se puede dar lugar a la precipitación de proteínas en forma de depósitos azulados, lo que se conoce como argiria (Kubba et al., 2013). El principal signo es el color azulado de la piel al quedar la plata retenida especialmente en las mucosas y la piel (Figura 6). Cuando reciben luz se cataliza en la zona más superficial el paso a plata elemental, que es de color azul.

Figura 6: Acumulación de plata en dermis (derecha) y epitelio duodenal (izquierda). Imagen adaptada de referencia (Kubba et al., 2013)

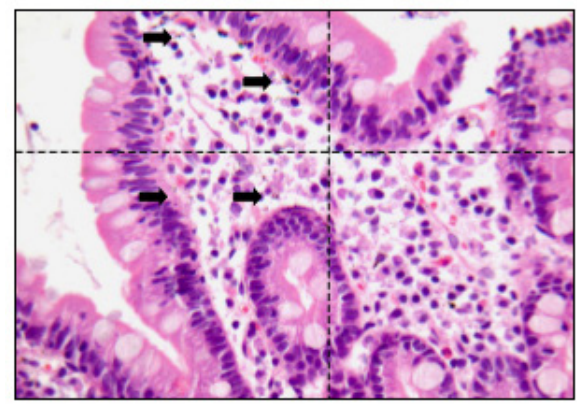

Ediciones Universidad de Salamanca / @®@®

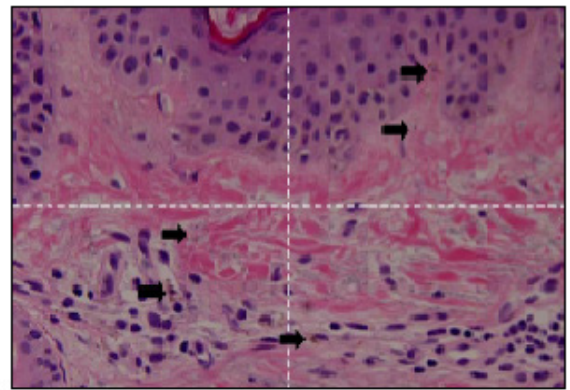

FarmaJournal, vol. 5, núm. 1 (2020), pp. 27-36 
Por ello, las personas que tienen esta enfermedad se caracterizan por presentar la piel de un tono azul/grisáceo. Antiguamente, las familias acomodadas usaban utensilios de plata para comer y con frecuencia desarrollaban esta enfermedad, por lo que se les decía que presentaban «sangre azul» (Alexander, 2009). Su diagnóstico se realiza principalmente mediante una biopsia (se observarán gránulos y depósitos de plata) ya que se puede confundir con una posible cianosis. Produce también metahemoglobinemia, hipocloremia e hiponatremia (Ducheyne, 2017).

El tratamiento a seguir ante la intoxicación por plata es el uso de selenio o azufre, ya que se unen a la plata formando complejos insolubles.

Pese a la toxicidad que posee la plata, hay que tener en cuenta que está presente en nuestra dieta diaria en el orden de 0,4-27 $\mu \mathrm{g} /$ día (Ducheyne, 2017) y que en condiciones normales el ser humano presenta entre 1 y $5 \mathrm{mg}$ de plata en el organismo. Además, la plata presenta un mayor efecto bactericida que citotóxico, ya que produce menor daño en células que en bacterias (Bartłomiejczyk et al., 2015). Esto se debe a que las células humanas presentan núcleo (que protege al ADN del efecto de la plata) y enzimas como la catalasa y la superóxido dismutasa (que neutralizan los ROS).

\section{Conclusiones}

El uso de la plata en forma de nanopartículas permite disponer de una herramienta para combatir posibles infecciones. En el caso concreto de infecciones en hueso, la inclusión de AgNPs en las matrices de los biomateriales cerámicos que conforman los implantes pueden disminuir la formación del biofilm, reduciendo así la necesidad de una segunda intervención quirúrgica. Además, las AgNPs presentan a su vez la ventaja de ser poco tóxicas para el organismo humano cuando están en forma de nanopartículas.

\section{Bibliografía}

Alexander JW. History of the Medical Use of Silver. Surg Infect (Larchmt). 2009; 10(3): 289-292.

Bartłomiejczyk T, Lankoff A, Kruszewski M, Szumiel I. Silver nanoparticles - Allies or adversaries? Ann Agric Environ Med. 2013; 20(1):48-54.

Chaloupka K, Malam Y, Seifalian AM. Nanosilver as a new generation of nanoproduct in biomedical applications. Trends Biotechnol. 2010; 28(11):580-588.

Chatterjee T, Chatterjee BK, Majumdar D, Chakrabarti P. Antibacterial effect of silver nanoparticles and the modeling of bacterial growth kinetics using a modified Gompertz model. Biochim Biophys Acta - Gen Subj. 2015; 1850(2):299-306. 
Chernousova S, Epple M. Silver as antibacterial agent: Ion, nanoparticle, and metal. Angew Chemie - Int Ed. 2013;52(6):1636-1653.

Ducheyne P. Comprehensive Biomaterials. 1. ${ }^{a}$ ed. II. Elsevier; 2017. pp. 81-87.

Gupta P, Sarkar S, Das B, Bhattacharjee S, Tribedi P. Biofilm, pathogenesis and prevention-a journey to break the wall: a review. Arch Microbiol. 2016; 198(1):1-15.

Hidron AI, Edwards JR, Patel J, Horan TC, Sievert DM, Pollock DA, et al. Antimicrobial-Resistant Pathogens Associated With Healthcare-Associated Infections: Annual Summary of Data Reported to the National Healthcare Safety Network at the Centers for Disease Control and Prevention, 2006-2007. Infect Control Hosp Epidemiol. 2008; 29(11):996-1011.

Kubba A, Kubba R, Batrani M, Pal T. Argyria an unrecognized cause of cutaneous pigmentation in Indian patients: A case series and review of the literature. Indian J Dermatology, Venereol Leprol. 2013; 79(6):805.

Lansdown ABG. Silver in health care: Antimicrobial effects and safety in use. Curr Probl Dermatol. 2006; 33:17-34.

Loza K, Diendorf J, Sengstock C, Ruiz-González L, González-Calbet JM, Vallet-Regi $\mathrm{M}$. The dissolution and biological effects of silver nanoparticles in biological media. J Mater Chem B. 2014; 2(12):1634.

Monge M. Nanopartículas de plata: métodos de síntesis en disolución y propiedades bactericidas. Investig Quim. 2009; (August):33-41.

Qing T, Mahmood M, Zheng Y, Biris AS, Shi L, Casciano DA. A genomic characterization of the influence of silver nanoparticles on bone differentiation in MC3T3-E1 cells. J Appl Toxicol. 2018; 38(2):172-179.

Salinas AJ, Vallet-Regí M. Evolution of ceramics with medical applications. Zeitschrift fur Anorg und Allg Chemie. 2007; 633(11-12):1762-1773.

Xiu Z, Zhang Q, Puppala HL, Colvin VL, Álvarez PJJ. Negligible Particle-Specific Antibacterial Activity of Silver Nanoparticles. Nano Lett. 2012; 12(8):4271-5.9.

Imágenes adaptadas de las siguientes referencias:

Chaloupka K, Malam Y, Seifalian AM. Nanosilver as a new generation of nanoproduct in biomedical applications. Trends Biotechnol. 2010; 28(11):580-858.

Kubba A, Kubba R, Batrani M, Pal T. Argyria an unrecognized cause of cutaneous pigmentation in Indian patients: A case series and review of the literature. Indian J Dermatology, Venereol Leprol. 2013; 79(6):805.

Loza K, Diendorf J, Sengstock C, Ruiz-González L, González-Calbet JM, Vallet-Regí $\mathrm{M}$. The dissolution and biological effects of silver nanoparticles in biological media. J Mater Chem B. 2014; 2(12):1634. 